\title{
Eugênio Gudin e as Influências Internacionais na Defesa de sua Agenda Econômica Liberal: o Hiperemprego e o Livre-Comércio
}

\section{Eugênio Gudin and the International Influences on the Defense of his Liberal Economic Agenda: Hyperemployment and Free Trade}

\author{
Ivan Gambus Faria ${ }^{\mathrm{a}}$ \\ Victor Cruz e Silva ${ }^{\mathrm{b}}$ \\ Marco Antonio Ribas Cavalieri ${ }^{\circ}$
}

\begin{abstract}
Resumo: O artigo tem por objetivo analisar as influências internacionais utilizadas por Eugênio Gudin na defesa de sua agenda econômica liberal. Gudin manteve contato constante com importantes economistas que trabalhavam na Europa e nos Estados Unidos, transmitindo e adaptando o que encontrava no que considerava a fronteira da ciência econômica para o cenário nacional. Analisamos dois temas centrais nos quais Gudin absorvia os desenvolvimentos da ciência econômica estrangeira para defender sua agenda liberal: sua teoria do hiperemprego e a defesa do livre-comércio.
\end{abstract}

Palavras-chave: Eugênio Gudin. Difusão de pensamento econômico. Liberalismo. Jacob Viner.

Abstract: The article aims to analyze the international influences used by Eugênio Gudin in the defense of his liberal economic agenda. As Gudin maintained constant contact with important economists working in Europe and in the United States, he continuously transmitted and adapted what he considered the edge of economic science to Brazil. We analyze two central themes in which Gudin absorbed the developments in the foreign economic science to defend his liberal agenda. Namely, we examine his theory of hyperemployment and the defense of free trade.

Keywords: Eugênio Gudin. Diffusion of economic thought. Liberalism. Jacob Viner.

JEL Classification: A1 1; B31.

\footnotetext{
a Pesquisador autônomo.

b Universidade Estadual de Ponta Grossa (UEPG), Setor de Ciências Sociais Aplicadas (SECISA), Departamento de Economia. Ponta Grossa, Paraná, Brasil.

c Universidade Federal do Paraná (UFPR), Setor de Ciências Sociais Aplicadas, Departamento de Economia. Curitiba, Paraná, Brasil.
} 


\section{1 lntrodução}

Eugênio Gudin pode ser considerado o grande pioneiro do estabelecimento mais moderno da economia como profissão e campo científico no Brasil. Engenheiro de formação, foi autodidata em economia. Assumiu uma das primeiras cátedras na área em 1939 e publicou, em 1943, o primeiro livro-texto de economia redigido em português para o público brasileiro, o Princípios de Economia Monetária (PEM). ${ }^{1}$ No ano de 1944, Gudin elaborou o currículo fundador do curso de graduação em Economia, o qual seria estabelecido na então Universidade do Brasil (atual Universidade Federal do Rio de Janeiro). Ainda na mesma década, ao ingressar na Fundação Getúlio Vargas, criou o Instituto Brasileiro de Economia (IBRE) e a primeira revista especializada na área, a Revista Brasileira de Economia (RBE). ${ }^{2}$

Como figura pública, na primeira metade dos anos 1940, ocupou o cargo de membro da Comissão de Planejamento Econômico e, durante oito meses, entre 1954 e 1955, no governo Café Filho, foi ministro da Fazenda. Durante sua longa carreira, esteve presente também no debate público como polêmico articulista de jornais, trabalhando durante mais de três décadas no jornal carioca $O$ Globo.

Buscando contribuir com a literatura sobre esse importante personagem da economia brasileira, nossa pesquisa concentra-se sobre a influência internacional na construção dos argumentos utilizados por Gudin para sustentar sua agenda econômica liberal. No auge de sua influência, as décadas de meados do século XX, seu debate se dava em oposição às teses intervencionistas dos desenvolvimentistas que dominaram o período chamado por Bielschowsky (2011) de primeiro ciclo ideológico do desenvolvimentismo. ${ }^{3}$ Marcando diferença metodológica com os autores desenvolvimentistas, o liberal brasileiro acreditava que não era preciso elaborar uma nova teoria para explicar a economia dos países periféricos da América Latina. Gudin argumentava que a teoria econômica desenvolvida nos grandes centros norte-americanos e europeus serviria perfeitamente para analisar e fazer recomendações tanto para os países desenvolvidos, quanto para os países mais atrasados, a exemplo do Brasil. Segundo

1 São encontradas diferentes afirmações sobre o pioneirismo do PEM na literatura. Simonsen (1979, p. 93), por exemplo, afirma que é o primeiro livro significativo de economia moderna escrito em português. Scalercio e Almeida (2012, p. 142), por sua vez, afirmam ter sido o primeiro texto moderno de macroeconomia escrito por um brasileiro.

2 Mais informações acerca da novidade que foi a RBE podem ser encontradas no site da própria Revista Brasileira de Economia e em Bielschowsky (1996, p. 38).

3 Neste trabalho, adotamos a interpretação historiográfica de Bielschowsky $(2000,2011)$, segundo a qual o desenvolvimentismo é uma ideologia de superação do atraso econômico através da combinação de Estado e mercado. Em especial, até meados dos anos 1960, o desenvolvimentismo significou a defesa de um projeto de industrialização integral planejada, induzido pelo Estado, como essência da estratégia de superação do subdesenvolvimento. Entre as ideias centrais desse primeiro desenvolvimentismo estão a proteção à indústria nascente e a contestação das teses de livre-comércio. 
Gudin (1952b), os economistas latino-americanos deveriam se guiar pela máxima "mesmas equações, diferentes parâmetros" (GUDIN, 1952b, p. 53).

É dentro disso que surge a motivação para este artigo, pois, em seus escritos artigos, sucessivas edições de seu livro-texto e comunicações pessoais -, nota-se uma constante atenção ao estudo do que Gudin considerava ser a fronteira do pensamento econômico. Cioso de estar em compasso com o pensamento econômico que considerava de fronteira, o liberal brasileiro prezava sobremaneira o contato com os economistas que estavam no "centro" da academia mundial - em oposição aos economistas da "periferia". Sua atuação, então, sempre foi marcada pelo contato constante com o exterior. Eugênio Gudin foi peça central da delegação brasileira em Bretton Woods, representante do Brasil no Fundo Monetário Internacional, membro ativo da Associação Econômica Internacional ${ }^{4}$ e integrante da Mont Pèlerin Society. ${ }^{5}$ Ele travou e manteve contato em variados graus de proximidade com grandes nomes da economia nos Estados Unidos e Europa, tais como Edward Bernstein, Maurice Byè, Milton Friedman, Gottfried Haberler, Friedrich Von Hayek, Douglass C. North, Ragnar Nurkse, Raúl Prebisch, Lionel Robbins, Theodore Schultz, Jacob Viner, e outros. Entre esses nomes, Viner e Haberler se destacam, pois nutriram longa e profícua amizade e contato profissional com o brasileiro.

Sendo assim, no que segue apresentamos como Gudin buscava ativamente acompanhar a produção acadêmica no exterior, trazendo para a defesa de sua agenda econômica elementos do que entendia como fronteira do conhecimento em economia monetária, macroeconomia e comércio exterior. Uma análise de todas as influências internacionais na extensa obra de Gudin, contudo, certamente ultrapassaria os limites de um artigo. Assim, escolhemos mostrar como Gudin tratou de gradativamente incorporar influências internacionais em dois temas fundamentais e recorrentes de sua agenda econômica liberal.

O primeiro tema no qual mostramos como Gudin incorporou a literatura internacional que considerava moderna é o desenvolvimento de seu conceito de hiperemprego. Tomamos esse tema como fundamental por duas razões. Por ser um conceito cunhado pelo próprio Gudin e, mais importante, por se relacionar com uma de suas preocupações mais fundamentais: a crônica pressão inflacionária à qual a economia brasileira estaria submetida. Gudin usava esse conceito para argumentar contra as políticas de investimento público em uma estratégia de industrialização forçada. Em um cenário no qual não havia mão de obra excedente disponível para

$4 \quad$ A Associação Econômica Internacional surgiu em 1950 como uma organização não governamental fundada sob o incentivo do Departamento de Ciências Sociais da Organização das Nações Unidas para a Educação, a Ciência e a Cultura (Unesco).

5 A Mont Pèlerin Society foi fundada em 1947, principalmente por Albert Hunold e Friedrich Hayek (este, seu primeiro presidente). Em meados do século XX, foi o principal think tank neoliberal a se opor às políticas do então crescente welfare state. Sobre a associação, ver Mirowski e Plehwe (2009). 
a indústria - o cenário de hiperemprego -, maiores gastos de investimento induzidos pelo governo retirariam mão de obra do setor mais produtivo da economia, o agrícola, além de, concomitantemente, induzir graves pressões inflacionárias.

Em segundo lugar, mostramos a incorporação das ideias trazidas do exterior no tema que foi mais recorrente nos debates de Gudin com autores desenvolvimentistas: o comércio exterior. Esse era o assunto mais caro àqueles que reivindicavam a industrialização induzida pelo Estado como via de desenvolvimento, pois o argumento mais importante para defesa dessa tese vem da refutação dos benefícios do livre-comércio, especialmente das vantagens comparativas. A tese da deterioração dos termos de troca e a necessidade de induzir uma industrialização protegida por tarifas está na base dos argumentos pró-industrialização na América Latina de meados do século XX. Nesse assunto, portanto, Gudin investiu bastante no intercâmbio de ideias com grandes nomes da academia americana, justamente no intuito de rebater o argumento de que a industrialização com proteção tarifária seria a principal, senão a única, via para superar o subdesenvolvimento.

Vale ressaltar, ainda, que este trabalho parece ser o primeiro, ao lado de Cruz e Silva, Cavalieri e Curado (2020), que conta com uma extensa pesquisa em fontes como as comunicações pessoais de Gudin, encontradas principalmente em seu arquivo pessoal, de posse da Fundação Getúlio Vargas, e nos Jacob Viner Papers, mantidos pela Universidade de Princeton. A maior parte das correspondências disponíveis trata de comunicações entre Gudin e Viner (vale notar que nessas comunicações Gudin discute com Viner sobre sua relação com outros grandes nomes da economia internacional).

Na segunda seção apresentamos brevemente o que consideramos o núcleo da agenda econômica liberal de Gudin, contextualizando a apresentação da agenda com alguns dos debates nos quais Gudin esteve envolvido. Depois, na terceira seção, apresentamos como Gudin incorporou gradativamente influências internacionais em suas argumentações a respeito do conceito de hiperemprego e no assunto da defesa do livre-comércio. A quarta seção encerra o artigo com algumas notas conclusivas.

\section{A Agenda Econômica Liberal de Eugênio Gudin}

De acordo com Bielschowsky (2001, p. 93), autor de Pensamento econômico brasileiro: o ciclo ideológico do desenvolvimentismo, e os mais recentes biógrafos de Gudin, Scalercio e Almeida (2012, p. 24), a tônica da obra de Gudin foi a difusão do liberalismo econômico para o contexto brasileiro. Sua agenda liberal nadava contra a corrente predominante durante meados do século passado no Brasil, o desenvolvimentismo. Em sua época, portanto, as ideias de Gudin formavam o campo minoritário do debate econômico local - como pode-se depreender da leitura de Bielschowsky (2000). Entre as várias ideias do que consideramos sua agenda liberal, os dois mais importantes 
pontos podem ser resumidos na condenação da intervenção estatal no sentido da industrialização e na defesa do livre-comércio (oposição ao protecionismo).

No que diz respeito à condenação da industrialização planejada induzida pelo governo, a série de textos em que essa discussão de Gudin ganha importância é tradicionalmente conhecida na história do pensamento econômico brasileiro como "a controvérsia do planejamento na economia brasileira". ${ }^{6}$ Além de Gudin, o outro protagonista foi o industrialista e patrono do desenvolvimentismo, Roberto Simonsen. É nesse debate que, pela primeira vez, Gudin recorre amplamente à literatura internacional. Ao contrário de Simonsen, que havia escrito um texto com poucas referências e bastante baseado no relatório da Missão Cooke, ${ }^{7}$ Gudin cita diversos autores norte-americanos e britânicos, clássicos e contemporâneos. Em nossa opinião, fica claro o desejo de Gudin de demonstrar que autores estrangeiros apoiavam suas teses liberais utilizando algo como um argumento de autoridade, calcado no fato de que norte-americanos e britânicos teriam desenvolvido o que havia de melhor e mais moderno na área. Esse expediente - de recorrer à retórica do conhecimento de fronteira vindo do estrangeiro - passaria a ser uma tônica no trabalho de Gudin.

Dentro dessa discussão sobre a industrialização da economia brasileira, é relevante marcar que Gudin não se posicionava contra a industrialização em si. Contudo, a indústria deveria se desenvolver somente caso não dependesse, ao menos no longo prazo, da ajuda do governo, pois, do contrário, corria-se o risco de promover uma indústria com baixa produtividade, já que estaria blindada da competição internacional (GUDIN, 1943b, 1952b, 1954b, 2010). Para Gudin, a questão da produtividade era fundamental. O liberal brasileiro insistia na necessidade de se promover políticas no sentido de aumentar a produtividade da economia, em especial no setor agrícola, o qual era então responsável pela maior parcela do produto nacional (GUDIN, 1943b, 1952b, 1954b, 2010). Ligado a esse tema da produtividade, Gudin advogava a favor do desenvolvimento da pesquisa aplicada para o descobrimento das reais necessidades do país (GUDIN, 1952b, 2010), bem como no sentido do provimento de ampla educação e ensino técnico (GUDIN, 1943b, 1954b, 2010).

No tocante à sua crítica ao projeto de industrialização, Gudin foi um intransigente defensor da abertura comercial. Ele criticava o protecionismo defendido pelos industriais brasileiros - parte importante do projeto de industrialização forçada. O protecionismo, segundo ele, prejudicava a solução do problema da baixa produtividade da economia (BIELSCHOWSKY, 2001, p. 97; VON DOELLINGER, 2010, p. 27). Adicionalmente, o liberal brasileiro era um grande crítico de uma das ideias cruciais da base dos argumentos pró-industrialização: a tese da deterioração dos termos de troca.

$6 \quad$ Sobre esse debate, ver Von Doellinger (2010).

7 Sobre a Missão Cooke, ver Oliveira (2003). 
Ele também combateu a tentativa de transferir para o Brasil as políticas protecionistas advogadas pelo então conhecido autor romeno Mihail Manoilescu, trazido ao debate brasileiro pelos defensores da industrialização, em especial Roberto Simonsen.

Em relação especificamente ao debate sobre as ideias da Comissão Econômica para a América Latina e o Caribe (Cepal), interessa marcar um episódio que mostra como Gudin fazia questão de recorrer aos economistas estrangeiros para auxiliá-lo na defesa de sua agenda liberal. Como editor da RBE, Gudin publicou uma tradução do famoso artigo de Prebisch (1949), no qual o argentino apresenta sua tese sobre a deterioração dos termos de troca. Porém, no mesmo ano dessa publicação, ele começa a operar para trazer Jacob Viner ao Brasil para uma palestra na qual as teses de Prebisch seriam criticadas. Em uma série de correspondências trocadas com Viner entre 1949 e 1950, Gudin convida-o a proferir uma palestra no Brasil, sugerindo-lhe que comentasse as teses de Prebisch.

Em 28 de setembro de 1949, Gudin escreveu para Viner:

I am now making arrangements on behalf of the Getulio Vargas Foundation and the Faculty of Economics of the University of Rio, with the American Embassy for a visiting Professor of Economics to come next summer (your summer, our mild winter) 1950, during July and August say, 2 months. Your name was the first one put forward by our Economic Committee and we would be delighted if you accepted (Gudin para Viner, 28 de setembro, 1950, Jacob Viner Papers).

Pouco menos de um mês depois, em 26 de outubro de 1949, Gudin emendaria seu convite a Viner, acrescentando a solicitação de comentários sobre as teses de Prebisch para publicação na RBE. Gudin escreveu:

This is simply to make a request and draw on your time (should it be possible) for the benefit of our Revista and enlightenment of Brazilian economists. I have asked my friend and colleague Bulhões, who is now in Washington (Shoreham Hotel) to send you an English copy of a very interesting paper written for CEPAL by the well known Argentine (sic) economist Prof. Raul Prebisch, which our Revista just published, under the title of "Latin America Development and its Main Problems". [...] What we would much appreciate for publication in our December issue (in which case it would have to be airmailed in the U.S.A. not later than 1st December) would be a comment of yours on the main points of Prebisch's papers (Gudin para Viner, 26 de outubro, 1949, Jacob Viner Papers).

Viner aceita o convite, e sua palestra proferida na segunda metade dos anos 1950, na Fundação Getúlio Vargas, é reconhecida como uma das primeiras contestações à tese da deterioração dos termos de troca na versão de Prebisch (OMAN; WIGNARAJA, 1991; DOSMAN, 2008; PERROTA, 2016). ${ }^{8}$ Consideramos impor-

$8 \quad$ Segundo Andrada, Boianovsky e Cabello (2018, p. 725), Furtado percebeu, na iniciativa de Gudin, o recurso a sumidades internacionais no sentido de abrir uma ofensiva no plano acadêmico 
tante mencionar esse episódio porque ele demonstra como Gudin recorria às suas relações com economistas dos Estados Unidos e Europa para contestar seus adversários da América Latina.

Gudin também se inquietava sobremaneira com o crônico processo inflacionário brasileiro. Aliás, a inflação sempre constituiu uma de suas principais preocupações, em especial no debate com a chamada interpretação estruturalista do balanço de pagamentos (GUDIN, 1943b, 1952b, 2010). Não por acaso, portanto, vários comentadores de sua vida e obra classificaram-no como um monetarista (BIELSCHOWSKY, 2001, p. 96; BOIANOVSKY, 2012, p. 283, 286, 316; CAMPOS, 1996, p. 38; LOUREIRO, 1996, p. 192-193; SCALERCIO; ALMEIDA, 2012, p. 207-208). ${ }^{9}$

A classificação de Gudin como monetarista não é, todavia, a única que aparece na literatura sobre seu trabalho. Como resumido por Cruz e Silva (2016, p. 34), diferentes autores classificam Gudin como influenciado pela escola austríaca, como neokeynesiano e, em um sentido retórico, até mesmo como desenvolvimentista, além de divergirem sobre o tipo de monetarismo do liberal brasileiro. Dentre as classificações, Celso Furtado apresenta a que nos parece a mais adequada. Em suas palavras: "Graças a seu sentido prático, [Gudin] não se perdia em disquisições à la Viner. Com facilidade, deslizava para a heterodoxia na argumentação, mas sem jamais ceder nas conclusões, sempre conservadoras [...]" (FURTADO, 1985, p, 142). Apesar de Furtado utilizar a palavra "conservadoras", consideramos que, não importando a matriz teórica que embasava as argumentações de Gudin, em seus escritos o fio condutor era sempre a defesa de sua agenda econômica liberal.

Os trabalhos seminais de Bielschowsky $(2000,2001)$ são dos poucos trabalhos que, de maneira mais moderna, buscam se aprofundar nas concepções de teoria econômica do liberal brasileiro. Apesar disso, as obras de Bielschowsky não aprofundam o aspecto da busca de Gudin pelo conhecimento nos grandes centros internacionais do pensamento econômico. Nosso intuito é, portanto, avançar na compreensão sobre a maneira como ele absorvia os trabalhos de pesquisadores estrangeiros daquilo que considerava a fronteira do conhecimento, sempre na defesa de sua agenda econômica liberal.

Cabe, finalmente, localizar ainda mais especificamente de qual debate envolvendo Gudin estamos tratando. Apesar de Boianovsky (2012) apresentar o liberal brasileiro como um monetarista oposto ao estruturalismo no que diz respeito à discussão sobre inflação e balanço de pagamentos, nosso foco recai sobre

contra as ideias da Cepal. Ainda de acordo com os mesmos autores, Furtado teria chamado o debate que Gudin tentava promover entre Viner e as ideias da Cepal de um diálogo de surdos.

9 Cruz e Silva (2016, p. 30-34) faz uma análise detalhada dos rótulos que as posições de Gudin receberam na literatura. No que diz respeito à sua classificação como monetarista, Bielschowsky (1996, p. 67) comenta que ele recebia esse rótulo de seus adversários estruturalistas, pois, segundo estes, o liberal desconsiderava a natureza estrutural da inflação brasileira e desprezava os efeitos das políticas estabilizadoras sobre a atividade econômica porque considerava a economia brasileira em hiperemprego. 
sua agenda liberal de forma mais ampla. Certamente, monetarismo e liberalismo apresentam intersecções, mas não os consideramos inteiramente coincidentes. A agenda liberal de Gudin considerada aqui se opõe ao desenvolvimentismo, ${ }^{10}$ e não ao que qualificamos como algo mais específico, o estruturalismo ao qual se opôs o monetarismo, tal como apresenta Boianovsky (2012). Estamos, portanto, tratando da dicotomia liberalismo-desenvolvimentismo, e não da oposição mais específica entre monetarismo e estruturalismo.

\section{Os Argumentos da Agenda Econômica de Eugênio Gudin e suas Influên- cias Internacionais}

Os exemplos das influências internacionais que mostramos nesta seção dividem-se em dois tópicos. O primeiro relaciona-se à incorporação gradativa de argumentos da ciência econômica produzida nos Estados Unidos e Europa ao argumento original de Gudin sobre a existência do que chamava de hiperemprego no Brasil. O segundo tópico desenvolve de forma mais pormenorizada as discussões relacionadas à defesa do comércio exterior livre e o combate às teses que defendiam ou embasavam a promoção de uma industrialização capitaneada pelo Estado.

\subsection{Hiperemprego}

O hiperemprego refere-se ao diagnóstico original de Gudin quanto ao comportamento do mercado de trabalho brasileiro. Embora essa expressão apareça pela primeira vez no relatório Rumos de Política Econômica, publicado em 1945, seria somente em um texto de 1958 que o autor definiria mais precisamente o conceito (GUDIN, 2010). Para ele, havia um desequilíbrio no mercado de trabalho brasileiro em que o emprego "gravitaria" em torno de $100 \%$. Isso ocorreria porque pessoas que não desejavam trabalhar em circunstâncias normais - tais como pessoas "do lar" e aposentadas - acabariam por ingressar no mercado de trabalho, dada a peculiar situação brasileira (On Inflation, 10 de setembro, 1958, Arquivos Pessoais de Eugênio Gudin). Em seus escritos, a situação de hiperemprego servia para argumentar contra programas públicos de investimentos, especialmente na direção de uma industrialização. Numa discussão de 1945 com o industrialista Roberto Simonsen, Gudin aventava a hipótese de que a situação de hiperemprego devia-se exatamente aos investimentos públicos exagerados levados a cabo pelo governo getulista (GUDIN, 2010, p. 89-91). ${ }^{11}$ No que segue, é interessante notar

10 Para a definição do que entendemos aqui como desenvolvimentismo, rever a nota de rodapé 1.

11 Segundo Boianovsky (2018, p. 6) e o site oficial do Instituto Brasileiro de Geografia e Estatística (IBGE), dados referentes a desemprego no Brasil estiveram disponíveis somente a partir do final da década de 1960, o que torna difícil julgar se Gudin estaria correto sobre sua classificação do hiperemprego no Brasil. 
como o conceito de hiperemprego vai incorporando influências internacionais, no sentido de, até mesmo na terceira edição do PEM, Gudin encaixá-lo como um dos equilíbrios possíveis dentro das então novas teorias keynesianas dos equilíbrios de pleno-emprego e subemprego.

Na segunda edição de seu livro-texto, o PEM de 1947 -, Gudin também menciona o chamado hiperemprego. Nessa edição, o autor faz simplesmente uma transcrição do conteúdo presente no documento de 1945 citado no Rumos. Algo a se notar sobre essa primeira vez em que o hiperemprego aparece no PEM, é que, apesar de ser um livro-texto, Gudin não adverte o leitor de que essa tese constitui parte da sua interpretação original da economia brasileira. Ele mistura sua interpretação com apresentação de outras teorias do emprego de autores internacionais (GUDIN, 1947, p. 168-170). ${ }^{12}$

Contextualizando suas influências internacionais, é preciso dizer que seria a partir da segunda metade da década de 1940 que Gudin travaria contato mais próximo com economistas dos grandes centros mundiais. Por exemplo, Gottfried Haberler esteve no Brasil em 1947 para auxiliar Gudin e Otávio Gouvêa de Bulhões na elaboração de um projeto de Banco Central. Nesse ano, a segunda edição de seu livro-texto já estava concluída. Contudo, no segundo volume que seria adicionado ao PEM em 1952, constituindo sua terceira edição, a influência dos economistas estrangeiros sobre Gudin fica bastante visível. ${ }^{13}$ No prefácio de 1952, Gudin assinala que muitos dos desenvolvimentos apresentados ali vieram de recomendações de Haberler (GUDIN, 1952a). Adicionalmente, Gudin relata a Viner ter encontrado a inspiração final para concluir o novo trabalho nas palestras ministradas por ele no Brasil, em 1950. Nas palavras do próprio Gudin: "After you left I made up my mind to finish writing the second volume of my Principles, which have been two-thirds finished for the last three years. I hope to hand over the manuscript to the Editor early next year, thank Goodness." (Gudin para Viner, 28 de novembro, 1950, Jacob Viner Papers). A influência de ambos os autores, inclusive com menções a obras específicas, é confirmada em outra correspondência de Gudin a Viner, escrita anos depois, na qual o economista brasileiro refletia quanto à formação de suas convicções liberais:

Naturally, I am considered Industry's $n^{\circ} 1$ enemy, which is not true, because I am only enemy number one of low productivity and high prices. This does not mean I am a 100\% free-trader. I believe in developing Brazil's industry; I agree with infant industry's policies etc. I would subscri-

12 Vale notar que, na primeira edição do PEM, de 1943, o conceito não aparece.

13 Após várias tentativas de encontrar o primeiro volume da terceira edição, chegamos à conclusão de que o segundo volume data de 1952, mas o novo primeiro volume do livro foi publicado apenas em 1954. O material de arquivo provê evidência de que esse seria mesmo o caso. Em sua correspondência com Jacob Viner, Gudin relata estar prestes a entregar a terceira edição completa do primeiro volume de seu livro-texto, atrasada havia dois anos (Gudin para Viner, 24 de dezembro, 1953, Jacob Viner Papers). 
be to every word you wrote in your 'Canada' II lecture [...]. I would also subscribe to what Gottfried [Haberler] writes in his Economic Journal's article of 1950 "Some Aspects [....]". If one introduces immobility of labor, non-competing groups, trade-union pressures and interference with free competition, then the picture is altered (Gudin para Viner, 29 de janeiro, 1959, Jacob Viner Papers).

Assim, na terceira edição do PEM (GUDIN, 1952a), a explicação das causas da peculiar situação do emprego no Brasil ganha um elemento monetário. Para o autor, o problema surgia da existência de uma massa monetária excessiva resultante do financiamento do setor público via incremento do déficit público frente aos fatores de produção disponíveis, resultando na realocação dos fatores através do aumento dos salários (GUDIN, 1952a, p. 80). Nesse estabelecimento da causa monetária do hiperemprego, o liberal brasileiro recorre a Knut Wicksell, o qual, segundo Boianovsky (2012, p. 289), Gudin tomava como defensor da teoria quantitativa da moeda. Os problemas gerados pelos excessos monetários seriam de duas ordens. O hiperemprego era acompanhado de inflação, mas também colocava os salários para além de sua produtividade. Os salários mais altos acarretavam má alocação do trabalho, reduzindo a produtividade da economia nacional. Portanto, nesse momento, Gudin estava tomando a tese da hiperinflação para criticar tentativas de aumentar o investimento via governo - especialmente usando aumento da base monetária. Não vemos, reiteramos, essa elaboração da tese da hiperinflação como parte da discussão entre as interpretações estruturalista e monetarista da inflação, debate que ocorreria apenas a partir do final dos anos 1950 (BOIANOVSKY, 2012, p. 284). Diante disso, é importante marcar que a discussão monetária da hiperinflação aparece nessa edição do PEM quando Gudin estava discutindo as teses de necessidade de investimento público advindas de Keynes (GUDIN, 1952a, p. 78-91).

Enquanto o uso de Wicksell remete às leituras mais clássicas empreendidas por Gudin, a influência de suas leituras então contemporâneas fica mais clara quando ele mostra o estado de hiperemprego como um dos equilíbrios possíveis partindo da condição de pleno-emprego, em especial notando como os equilíbrios em economia são instáveis. A partir do ponto de pleno-emprego, ou a economia se afastaria desse ponto, entrando em declínio, ou tenderia ao hiperemprego, dito por ele como sinônimo de inflação. Em relação a isso, Gudin utiliza largamente os conceitos keynesianos de multiplicador e instabilidade do pleno-emprego (GUDIN, 1952a, p. 216-226). Gudin foi pioneiro na difusão do pensamento de Keynes e dos primeiros keynesianos europeus e norte-americanos no Brasil (CRUZ E SILVA; CAVALIERI; CURADO, 2020). Nesse exemplo, então, é possível notar como ele tentava compatibilizar sua interpretação da economia brasileira no arcabouço da economia keynesiana, utilizando tanto Keynes, propriamente, quanto artigos de 
Viner (1950) e Haberler (1948) (GUDIN, 1952a, p. 215-216). ${ }^{14}$ Entendemos ser relevante notar como Gudin, ao incluir seu conceito de hiperemprego como um dos equilíbrios possíveis, faz uma tentativa de colocar seu conceito no modelo de diferentes equilibrios possíveis presente nos trabalhos de Keynes. Inclusive, adicionalmente, vale notar que Gudin faz um esforço consciente de apresentar as teorias de Keynes e keynesianas na terceira edição do PEM, o que não havia feito a contento nas edições anteriores - como ele mesmo relata a Prebisch:

Recebi com muito especial prazer sua carta de 26 de Junho, acompanhada da agradável surpreza (sic) de uma cópia à máquina de seu novo compêndio sobre a Teoria Keynesiana, a qual vou ler com avidez, não só pelo interesse do assunto e do Autor, mas ainda porque ele está diretamente ligado à matéria do $2^{\circ}$ Volume de meu "Princípios de Economia Monetária" (de que lhe mandei recentemente o $1^{\circ}$ Volume), cujos primeiros capítulos estou agora escrevendo (Gudin para Prebisch, 2 de julho, 1947, Raúl Prebisch Papers). ${ }^{15}$

É importante notar que, já no texto de 1945, em discussão com Simonsen, Gudin faz uma interessante análise de como passou a entender os equilíbrios em economia como instáveis ao estudar autores da economia keynesiana. De acordo com Gudin (2010, p. 88-90), o que diferenciava a economia dos clássicos como Ricardo, Say e Mill do que então seria a nova fronteira da disciplina era justamente o entendimento de que os equilíbrios econômicos eram instáveis. Como autores dessa nova economia, Gudin (2010, p. 89) cita, além de Keynes, Dennis Robertson, Alvin Hansen e o próprio Haberler (GUDIN, 1952a, p. 213-217). A leitura desses autores por parte de Gudin mostra que o brasileiro não estava apenas tentando interpretar Keynes a partir dos trabalhos originais, mas estava a par da produção derivada dos trabalhos do britânico, adaptando conceitos e modos de argumentação para defender ideias relativas à economia brasileira.

14 Nota-se que os trabalhos de Viner e Haberler foram publicados justamente entre o lançamento da segunda edição do PEM (GUDIN, 1947) e o lançamento do segundo volume da terceira edição (GUDIN, 1952a). O primeiro desses é um artigo de Viner (1950) intitulado "Full employment at whatever cost". O segundo é a coletânea de conferências de Haberler (1948).

15 A comunicação entre Gudin e Prebisch, via de regra, era feita com o brasileiro escrevendo em português para o argentino, e o argentino escrevendo em espanhol para o brasileiro. 


\subsection{Comércio Internacional e a Industrialização Brasileira}

No tema do comércio internacional, a agenda econômica de Eugênio Gudin era voltada para a construção de um sistema de livre-comércio em que o Brasil valorizasse sua especialização agrícola, que deveria ser, então, a principal via de crescimento da renda nacional (GUDIN, 1952b, 1965, 2010). O liberal não defendia, todavia, a especialização completa do Brasil em agricultura. Para ele, a economia brasileira deveria ser mista.

Nesse assunto do comércio internacional, Gudin vai combater principalmente duas ideias. Primeiro, vai tratar de criticar o protecionismo recomendado por Mihail Manoilescu, economista romeno que defendia tarifas protetivas permanentes como forma de transferir fatores produtivos para a indústria. A hipótese básica de Manoilescu é que a indústria seria sempre mais produtiva que a agricultura. A partir disso, em carta para Viner, Gudin afirma que "[...] Brazil has been and still is a Manoilesco's paradise [...]", no qual se almejava de maneira descabida a industrialização (Gudin para Viner, 29 de janeiro, 1959, Jacob Viner Papers). Gudin também atacava a teoria da deterioração dos termos de troca usada como argumento base para defesa da industrialização dos países da América Latina. Analisamos, a seguir, as ideias a respeito do comércio exterior, mostrando a sua evolução a partir da década de 1940.

\subsubsection{As Primeiras Ideias Livre-Cambistas e o Ataque às Teses de Manoilescu: a Dé- cada de 1940}

Tomemos o texto de Gudin apresentado no $1^{\circ}$ Congresso Brasileiro de Economia (1943) bem como o texto já mencionado, Rumos de Política Econômica, de 1945 (GUDIN, 2010), como ilustrativos das posições iniciais do liberal brasileiro no tocante ao comércio exterior. Dentro da leitura desses textos, vale assinalar que ambos foram escritos no contexto do conflito da Segunda Guerra Mundial, um cenário anômalo do ponto de vista econômico, político e de relações internacionais.

Tanto no texto de 1943 quanto na resposta a Simonsen de 1945, Gudin nota que o Brasil não seria como a Argentina, cujos solos e terrenos são plenamente adequados a uma agricultura naturalmente de alta produtividade. Por isso, a produção brasileira deveria ser orientada no sentido de uma economia mista, composta de indústria e agricultura (GUDIN, 1943b, p. 324, 2010, p. 106-107). Para essa industrialização, tarifas protetivas deveriam ser admitidas, desde que se procurasse, através de estudos periódicos e revisões da proteção, utilizá-las no sentido de promover o aumento de produtividade da indústria nacional (GUDIN, 1943b, p. 328, 2010, p. 122-123). Finalmente, para qualificar qualquer ideia de liberalismo puramente radical que se possa atribuir a Gudin nesse campo, vale notar que, com base em 
Dennis Robertson, ${ }^{16}$ ele sustentava que havia de fato uma prejudicial instabilidade dos preços dos produtos primários em comparação com a estabilidade dos produtos industrializados. Mais ainda, essa instabilidade provocava um efeito cíclico entre as economias centrais e periféricas, justificando o estabelecimento de organismos internacionais que auxiliassem na manutenção da estabilidade dos preços dos produtos primários, ideia que Gudin atribuía ao plano que Keynes apresentou na conferência de Bretton Woods (GUDIN, 1943b, p. 326-328, 2010, p. 97).

No que segue do relatório Rumos, há um trecho interessante para compreender o valor que Gudin dava à atualização dos argumentos de acordo com a mais moderna teoria internacional. Em certa parte do relatório, criticando Simonsen, Gudin (2010, p. 69) diz: "Deixando de lado grandes economistas americanos, como Taussig, Bernstein e Viner e tantos outros, o presidente [Simonsen] ${ }^{17}$ apelou para 'inovadores' que passaram a constituir o brain trust [de Franklin D. Roosevelt], George Soules, Stuart Chase, Tugwell, etc". Aqui valem duas observações. Primeiro, Gudin parece desprezar os "inovadores" citados por Simonsen. Contudo, na década de 1930, esses economistas, que podem ser ligados à tradição institucionalista, faziam parte do mainstream da plural economia norte-americana, pois a abordagem institucionalista não era naquele tempo uma tradição heterodoxa, mas estava presente no governo e nos principais centros da academia, como detalhadamente argumenta Rutherford (2011). Assim, seria natural que, ao procurar referências de fronteira, em especial no assunto de planejamento econômico, Simonsen esbarrasse com autores institucionalistas. Em segundo lugar, a despeito de podermos certamente colocar Taussig no rol dos grandes economistas norte-americanos, ele não fazia parte da economia mais moderna que estava sendo construída por nomes como Viner, a quem orientou em Harvard. Taussig faleceu em 1940 e fazia parte da geração de economistas que ainda não tinha os dois pés fincados na tradição neoclássica (como eram os casos de Viner e Haberler). De acordo com Schumpeter, Cole e Mason (1941, p. 358) - Schumpeter foi o sucessor de Taussig na direção do departamento de economia de Harvard -, ele foi alguém que viveu na transição entre a economia clássica e a neoclássica.

O nome de Taussig é citado em mais três trechos do relatório Rumos. Em todas elas, os argumentos de Taussig trazidos são bastante simples. Por exemplo, Gudin utiliza Taussig para criticar a ideia que chama de "mercantilista", de acordo com a qual, para reduzir exportações, os fatores deveriam ser redirecionados para a substituição de importações. Coloca Gudin (2010, p. 98): "Se, para evitar as importações orientam-se esses fatores para a produção de consumo doméstico,

16 Nesse tocante, Gudin cita a obra Economic Essays and Addresses, de Arthur Cecil Pigou e Dennis Robertson (1931)

17 Na época do debate, Roberto Simonsen era presidente do Conselho Nacional de Política Industrial e Comercial. 
eles farão falta na produção para a exportação, o que acabará reduzindo não só as importações, mas as exportações também".

Outro exemplo da apropriação, por parte de Gudin, dos argumentos de autores da academia internacional para defender suas posições aparece no combate que o liberal brasileiro empreende contra as ideias de Mihail Manoilescu. ${ }^{18}$ No debate de 1945, Simonsen utiliza as teses do romeno, entre outros autores, para defender um projeto de industrialização da economia brasileira levada a cabo através do planejamento organizado pelo governo, sendo, então, rebatido por Gudin no texto Rumos. ${ }^{19}$ Em artigo relativamente recente, Joseph Love (2009) analisa tanto o espraio das teses de Manoilescu, bem como a recepção e as críticas que suas teses receberam de economistas como, por exemplo, Bertil Ohlin e Jacob Viner. Nesse tocante, chama a atenção como Gudin, em um tempo no qual a economia propriamente acadêmica era muito pouco desenvolvida no Brasil, foi capaz de seguir a discussão internacional e utilizar a literatura publicada sobre o trabalho de Manoilescu para rejeitar as ideias do romeno que Simonsen procurava transmitir no Brasil.

Podemos dividir a defesa do protecionismo e da industrialização por parte de Manoilescu em dois elementos. Primeiro, o economista romeno considerava o setor industrial mais produtivo que o setor agrícola em quaisquer circunstâncias, o que justificava a transferência forçada de fatores de produção deste para aquele. Ele baseava esse argumento no que chamava de superioridade do capital específico aplicado à indústria, o que, em termos simples, significava que maior quantidade de capital por trabalhador era aplicada na indústria em relação à agricultura. Empiricamente, Manoilescu argumentava que a produtividade da indústria seria cerca de quatro vezes maior que a da agricultura. Porém, nos países subdesenvolvidos não havia a transferência de recursos da agricultura para a indústria porque o diferencial de salários indústria-agricultura seria de cerca de 4,8 vezes, enquanto o mesmo diferencial relativo aos lucros seria de apenas 1,8 vezes. Em segundo lugar, Manoilescu procurou demonstrar que havia uma falha na demonstração das vantagens comparativas apresentada por Ricardo. Incorporando preços e salários à demonstração de Ricardo, Manoilescu argumentava que o exemplo ricardiano apenas mostrava que cada país - no caso do exemplo clássico de Inglaterra e Portugal - estava se especializando nas respectivas indústrias mais produtivas - vinho para Portugal e tecidos para a Inglaterra.

18 O livro importante de Manoilescu sobre o assunto do comércio internacional e industrialização se chama Teoria do Protecionismo e da Permuta Internacional. Publicado originalmente em 1929, foi traduzido para o português pelo Centro das Indústrias de São Paulo em 1931. Para maiores informações sobre o pensamento de Manoilescu, recomendamos Bobulescu (2003), Curi e Cunha (2015), Love (1996, 2009) e Maneschi (2008).

19 Manoilescu é apenas um dos muitos autores estrangeiros utilizados por Simonsen. Entre esses outros autores, vale mencionar também o uso das teses de Friedrich List. Para uma revisão mais abrangente dos autores que influenciaram Simonsen, ver Cavalieri e Curado (2016) e Curi (2015). 
No texto em que responde a Simonsen, Gudin (2010) realiza uma apropriação dos argumentos de Viner (1932) através da incorporação de traduções literais de trechos do artigo do economista norte-americano. O texto de Viner (1932) é a resenha que o economista escreveu sobre o livro Teoria do Protecionismo e da Permuta Internacional para o Journal of Political Economy. Uma comparação entre as tabelas e explicações de Viner (1932, p. 123-125) e as demonstrações e argumentações de Gudin (2010, p. 101) mostra que o economista brasileiro apenas transcreveu as tabelas de Viner, copiando parte de sua demonstração sobre o erro de Manoilescu. Apesar de utilizar as mesmas tabelas, a explicação de Gudin (2010, p. 101-102) é simplificada em relação à resenha de Viner. O brasileiro, em primeiro lugar, mistura de forma pouco clara os dois elementos presentes na justificação da necessidade de industrialização e protecionismo de Manoilescu. Gudin (2010, p. 101) diz que, segundo Manoilescu, a demonstração de Ricardo estaria errada porque a indústria teria superioridade intrínseca. Isso é verdade. Porém, na crítica sofisticada de Viner (1932), esse aspecto é comentado apenas en passant. O cerne da questão está na suposição de Manoilescu de que os salários nos dois setores, nos dois países, bem como os preços dos produtos continuariam os mesmos depois de estabelecido o comércio ou, mesmo, depois da especialização. Gudin (2010, p. 102) mostra exatamente esse problema, mas de forma bastante simplificada em relação ao argumento de Viner (1932). Na segunda edição do PEM, Gudin (1947, p. 252-253) repete a mesma crítica ao argumento de Manoilescu.

Ainda, é interessante notar que Gudin (2010, p. 100) cita outros dois autores que foram fundamentais no debate entre livre-comércio e protecionismo na primeira metade do século XX: Ohlin e Haberler. No caso do primeiro, Love (2009, p. 111) o coloca como principal autor contemporâneo que formula críticas ao trabalho de Manoilescu. Em seguida, Love (2009, p. 111-112) também nota como Viner havia refutado as teses do economista romeno em sua resenha. Nesses pontos, o que desejamos mostrar é o fato de que Gudin acompanhava a discussão mundial sobre os temas de sua agenda, procurando argumentos em trabalhos de autores que estavam justamente discutindo assuntos pertinentes à sua agenda nos principais periódicos e centros da economia acadêmica mundial. Mais à frente, já na década de 1950, Gudin vai retomar a discussão sobre o protecionismo, provocada pela publicação do trabalho de Everett Hagen (1958).

\subsubsection{O Aprofundamento da Relação com Jacob Viner no Contexto dos Anos 1950}

No ano de 1950, Jacob Viner esteve no Rio de Janeiro para uma palestra. As fontes pesquisadas, em especial as correspondências pessoais de Gudin, mostram que, após a visita do economista canadense, a interação entre ele e o brasi- 
leiro se intensificou. ${ }^{20}$ Em suas exposições no Brasil, publicadas integralmente na RBE, Viner (1951a, 1951b) comentou criticamente a então recém-lançada tese de Prebisch-Singer. ${ }^{21}$ Com a intenção de trazer a perspectiva de alguém importante na academia internacional, Gudin foi quem sugeriu a Viner que tratasse da tese da deterioração dos termos de troca em suas conferências no Brasil (Gudin para Viner, 26 de outubro, 1949, Jacob Viner Papers; Gudin para Viner, 25 de janeiro, 1950, Jacob Viner Papers). Oman e Wignaraja (1991) e Perrota (2016) ressaltam que, durante essas conferências, Viner estava apresentando o que havia de mais moderno na discussão sobre comércio exterior, principalmente no que tange aos países subdesenvolvidos. Um dos textos expostos por Viner (1951a) intitula-se "Tendências recentes na teoria do mecanismo do comércio internacional". Portanto, essa é mais uma evidência de que Gudin efetivamente empreendia esforço no sentido de trazer para a audiência brasileira o que estava na fronteira do pensamento econômico mundial, inclusive traduzindo para o português e publicando o conteúdo das exposições do professor estrangeiro.

Como a tese de Prebisch-Singer servia de suporte à ideia de que o caminho para o crescimento da renda em países como o Brasil se daria através da industrialização, a contribuição de Viner no sentido de suportar a agenda econômica de Gudin foi a de apontar outras barreiras ao crescimento que estariam além das relações de trocas desfavoráveis.

Entre esses obstáculos, na opinião de Viner (1951b, p. 202-203), estava o crescimento demográfico acelerado. Para o então professor de Princeton, em um cenário de rápido crescimento populacional, seria muito difícil fazer a renda per capita crescer substancialmente. A solução para o problema do crescimento acelerado da população estaria, segundo Viner (1951b, p. 203), na melhoria da educação e das condições de vida. Contudo, a educação e as condições de vida seriam dependentes do aumento da renda, formando um ciclo vicioso difícil de ser rompido.

Ainda relacionado ao argumento do problema populacional, Viner (1951b, p. 200) também questionava a relevância da Lei de Engel para explicar a deterioração dos termos de troca. Ele sustentava que haveria barreiras ao crescimento se,

20 Conforme as correspondências indicam, Jacob Viner e Eugênio Gudin tiveram seu primeiro contato em um jantar realizado na casa do professor Oskar Morgenstern, em 1949. Gudin foi introduzido a Viner por Haberler, quem era seu anfitrião nos Estados Unidos à época. Nessa mesma ocasião, o brasileiro convidou Viner para a realização da conferência no Brasil (Gudin para Viner, 28 de setembro, 1949, Jacob Viner Papers).

21 Prebisch, embora tenha sido convidado desde 1947 para empreitada semelhante, nunca atendeu aos convites para realizar conferências e estudos específicos no Rio de Janeiro (Gudin para Prebisch, 2 de julho, 1947, Raúl Prebisch Papers; Gudin para Prebisch, 21 de outubro, 1947, Raúl Prebisch Papers). Em julho de 1947, por exemplo, Gudin escreveu a Prebisch: "Tenho assim a satisfação de convidar o prezado amigo e sua Exma. Senhora a vir fazer no Rio de Janeiro um estágio de 60 dias, digamos, para organizar um projeto e uma memória justificativa do novo Banco Central, assunto em que a sua alta competência é reconhecida em todo o Continente" (Gudin para Prebisch, 2 de julho, 1947, Raúl Prebisch Papers). 
e somente se, a oferta dos países de produção primária aumentasse desproporcionalmente ao aumento da demanda nos países centrais. Esse aumento desproporcional, pensava Viner (1951b, p. 200-204), era um problema principalmente de crescimento populacional, uma vez que o setor primário absorvia a maior parte da população economicamente ativa, acarretando, portanto, o aumento desproporcional da oferta interna e de exportação.

A restrição demográfica ao crescimento seria incorporada por Gudin (1952a, p. 259-261) na terceira edição do PEM. Ele incluiu o elemento demográfico em sua importante lista de fatores responsáveis pela instabilidade e pelos obstáculos ao desenvolvimento. Nas edições anteriores, em que havia a lista, ele não contemplava essa dimensão (GUDIN, 1943a, p. 345, 1947, p. 273-277). Nesse ponto, pensamos que isso pode qualificar a opinião de Bielschowsky (2000, p. 49-50), segundo a qual um desenvolvimentista concordaria com os pontos da lista de Gudin. No contexto em que o fator demográfico foi adicionado à lista de Gudin, ele servia justamente para mitigar a relevância do problema da deterioração dos termos de troca e para mostrar o crescimento populacional como uma barreira que não seria superada apenas com as políticas então tradicionalmente recomendadas pelos desenvolvimentistas.

Nesse assunto ainda, Viner (1951b, p. 199-200) também argumentava que a educação deveria levar à modernização produtiva da agricultura, aumentando sensivelmente a produtividade desse setor nas economias da América do Sul. Em oposição às teses industrialistas, como as que buscavam apoio em Manoilescu, Viner procurou combater a ideia de que não haveria progresso técnico na agricultura, citando o caso de regiões e países desenvolvidos com notável progresso técnico nessa atividade. Viner (1951b, p. 199), repisando a contestação à tese de que a indústria é sistematicamente mais produtiva que a agricultura, afirmava:

Todavia, não conheço base alguma que justifique a aceitação da proposição de que existe qualquer tendência para o progresso tecnológico ser mais rápido na indústria manufatureira que na agricultura, salvo se essa tendência é consequência - e não causa - do fato de os países mais adiantados tecnologicamente serem frequentemente mais industriais que agrícolas. Não existe, de meu conhecimento, nenhum atraso marcado na tecnologia da agricultura da Dinamarca, da Inglaterra, da Nova Zelândia ou de Iowa.

Durante a carreira de Gudin, a produtividade sempre foi um tema bastante presente. Na opinião de Bielschowsky (2000, p. 92) esse tema organizava toda sua visão sobre o subdesenvolvimento brasileiro. Mesmo antes do debate com Simonsen, no texto apresentado no $1^{\circ}$ Congresso Brasileiro de Economia, Gudin trata do ponto da produtividade já afirmando que tanto na agricultura quanto na indústria a questão central era sempre o aumento da produtividade (GUDIN, 1943b). Esse tema reaparece na discussão com Simonsen (GUDIN, 2010). Contudo, na primeira edição do PEM (GUDIN, 1943a), a questão da produtividade não aparece como grande tema. 
Seria em 1954, após as conferências de Viner, no longo texto "Produtividade", publicado na RBE, que Gudin trataria pormenorizadamente da questão (GUDIN, 1954a). Inclusive, ele o faz utilizando o mesmo argumento de Viner, relacionando economias avançadas e produtividade agrícola. Nesse tocante, Gudin (1954a, p. 22) procurou arrolar dados que suportassem essa tese de que a produtividade da agricultura não é sempre inferior à da indústria. Ele recorre a dados de Colin Clark $^{22}$ - sem citar o trabalho específico do qual teria obtido os dados -, argumentando que três dos sete países de mais alta renda no mundo seriam preponderantemente agrícolas: Nova Zelândia, Argentina e Austrália. Adiciona a isso que seria um condado agrícola de Iowa a economia local de maior renda dos Estados Unidos. Para esse texto, Gudin solicitou o parecer de Viner, o qual chegou quando o brasileiro já ocupava o cargo de ministro da Fazenda. O tom geral da comunicação de Viner é de concordância com o conteúdo do artigo de Gudin: "I have finally found the time to read your manuscript. As with everything from your pen that I see, it was stimulating and largely persuasive." (Viner para Gudin, 23 de agosto, 1954, Jacob Viner Papers). ${ }^{23}$

Outro episódio de interesse para afirmar como Gudin estava atento às discussões na fronteira do pensamento internacional é sua preocupação com a publicação do artigo "An economic justification of protectionism”, de Everett Hagen (1958). Segundo Love (2009, p. 113), essa pesquisa constituiu mais um importante capítulo do debate sobre protecionismo versus livre-comércio como estratégias de aumento da renda. Hagen apresenta um modelo e uma demonstração empírica sobre a tese de que o protecionismo poderia levar ao aumento da renda nacional. Possivelmente por causa do fato de Hagen, um professor do Massachusetts Institute of Technology, ter demonstrado, em um artigo publicado no Quarterly Journal of Economics, o mecanismo de Manoilescu no formato da teoria neoclássica de ponta, além de ter testado a hipótese utilizando econometria, Gudin escreve para Viner a fim de obter argumentos que poderiam combater os resultados do artigo (Gudin para Viner, 29 de janeiro, 1959, Jacob Viner Papers). Aqui, a comunicação entre o brasileiro e o professor de Princeton é surpreendente, pois Viner escreve cerca de dois meses depois dizendo que não conhecia a publicação de Hagen (1958) - cuja primeira seção se intitula "Manoilesco, Viner, and Haberler":

22 Colin Grant Clark (1905-1989) foi um britânico e australiano especialista em contas nacionais e pioneiro nos cálculos de produto e renda.

23 Aparentemente, o pedido de pareceres de amigos e colegas do exterior era uma prática frequente à frente da RBE. Para publicar o famoso texto de Prebisch na revista, o brasileiro solicitou pareceres tanto de Viner quanto de Haberler: "Prebisch wrote a paper which we are going to publish in the Revista for December, on the economics of Latin-America. The Foundation desires to have two considered reviews of it by first class professors. So I asked Haberler (who accepted) and I am now asking you to do it. If you agree (I hope you will) I will send you the full text in English." (Gudin para Viner, 27 de dezembro, 1950, Jacob Viner Papers). 
I do not subscribe to the Q.J.E., and had not read Hagen's article when your letter arrived. Since then, whenever I have looked for the library copy, it was in circulation or misplaced. I will at once borrow a copy from a colleague, and will plan to send you my comments in a few days (Viner para Gudin, 16 de março, 1959, Jacob Viner Papers).

Isso mostra que Gudin estava mesmo bastante atualizado em relação ao que era publicado no exterior. Infelizmente, não encontramos nos arquivos outra resposta de Viner a Gudin com comentários ao trabalho de Hagen.

\subsubsection{Outras Influências do Pensamento Internacional no Tema do Comércio Exterior}

A terceira edição do primeiro volume do PEM, que foi lançada apenas em 1954, também incorporou algumas modificações baseadas no contato de Gudin com pensadores internacionais. Em correspondência com Viner, o brasileiro conta que mantinha contato com o economista Howard Sylvester Ellis, da Universidade de Berkeley, também ex-orientando de Taussig e presidente da American Economic Association, em 1949 (Gudin para Viner, 16 de agosto, 1955, Jacob Viner Papers). O volume organizado por Ellis em cooperação com Lloyd Meltzer, Readings in Theory of International Trade, foi influente nas modificações dessa edição do primeiro volume. A parte dedicada ao estudo dos câmbios foi inteiramente remodelada conforme Gudin notou no prefácio (GUDIN, 1954a). Baseado no texto de Machlup (1940), que integra também a coletânea organizada por Ellis e Meltzer, ele passou a apresentar, na parte sobre balanço de pagamentos, a chamada abordagem das elasticidades. Nesse ponto, Gudin faz uma ligação do seu livro-texto com um artigo publicado na RBE (SILVA, 1949), em que o autor faz um estudo da demanda norte-americana pelo café brasileiro.

O economista estoniano Ragnar Nurkse também aparece influenciando Gudin em pontos específicos. Apesar das semelhanças entre o pensamento de Nurkse e dos estruturalistas, Gudin encontrou no trabalho do estoniano argumentos contra a estratégia de industrialização dos desenvolvimentistas, a substituição de importações. ${ }^{24}$ Gudin relata a Viner as discussões suscitadas pela conferência de Nurkse no Rio de Janeiro - no encontro da Associação Econômica Internacional, organizado por Gudin - sobre a defesa da estratégia do crescimento equilibrado:

One of the interesting topics discussed was that referred in the last pages of Nurkse's and in the last sentences of mine, namely the Prebisch thesis that when you shift from consumption to investment you create a pressure on the balance of payments (due to investment demanding a larger share of imports than consumption (Gudin para Viner, 3 de setembro, 1957, Jacob Viner Papers).

24 Sobre o debate envolvendo Nurkse, ver Boianovsky (2012, p. 295-297) e Primi (2009). 
De acordo com o relato de Gudin, observamos como o brasileiro aprendeu um contra-argumento à tese da necessidade de promover uma generalizada substituição de importações a fim de promover a industrialização - como combatido pela política de crescimento balanceado de Nurkse. Dessa forma, Gudin adquiriu um novo contra-argumento à tese cepalina de que haveria na América Latina uma tendência ao aumento da propensão a importar como consequência do aumento dos investimentos, o que justificaria a intensificação da industrialização capitaneada pelo governo, a fim de contrabalançar a pressão no coeficiente de importações.

O assunto reaparece na participação de Gudin no encontro da Mont Pèlerin Society em 1958. Nesse evento, Gudin apresentou críticas ao argumento cepalino de que o problema da região consistiria no aumento da propensão a importar (Agriculture, 10 de setembro, 1958, Arquivos Pessoais de Eugênio Gudin). O economista brasileiro chamou atenção para a possibilidade de que, assumida razoável mobilidade interna de fatores, uma redução no consumo doméstico - portanto, aumento da poupança, como preconizavam os liberais - proporcional ao aumento dos investimentos liberaria fatores de produção para a produção de exportáveis sem pressionar a propensão à importação (Agriculture, 10 de setembro, 1958, Arquivos Pessoais Eugênio Gudin). Para essa conclusão e para esse aperfeiçoamento da crítica de Gudin à substituição de importações, as críticas de Nurkse ao argumento de que um aumento dos investimentos acarretaria aumento da propensão a importar foi crucial.

\section{Considerações Finais}

Comentando sobre o conceito da vulnerabilidade à inflação da economia brasileira, tese avançada por Otávio Gouvêa de Bulhões e desenvolvida por Gudin e Roberto Campos, Boianovsky (2012, p. 286) afirma que os monetaristas latino-americanos não somente importavam ideias do exterior, mas também as adaptavam às realidades das economias nacionais. Pensamos que esse é exatamente o caso que mostramos sobre Gudin por meio dos exemplos mencionados.

A necessidade do contato constante com os desenvolvimentos que ocorriam nos grandes centros produtores do conhecimento em economia foi marcante na carreira do liberal brasileiro. Assim, além de ter instalado o primeiro curso de graduação em economia, elaborando seu currículo - com a ajuda de especialistas internacionais -, Gudin procurou permanentemente transmitir para a audiência brasileira aquilo que considerava a fronteira do conhecimento na disciplina. $\mathrm{O}$ fato de Gudin ter sido o primeiro a escrever um livro-texto em português, em uma época em que poucos brasileiros sabiam ler uma língua estrangeira, também demonstra sua intenção de transmitir conhecimento de ponta para os interessados em economia no país. Notamos, da mesma forma, como em várias instâncias a argumentação na defesa de sua agenda econômica para o Brasil absorveu elemen- 
tos teóricos e metodológicos da literatura internacional. As sucessivas edições do PEM são testemunhas desses desenvolvimentos. Autores do porte de Jacob Viner e Gottfried Haberler mantinham contato com Gudin, auxiliando-o na construção de contra-argumentos para o debate com o pensamento brasileiro dominante à época, o desenvolvimentismo. Organizar a primeira publicação científica no Brasil, a RBE, bem como trazer diversos economistas estrangeiros para conferências no Brasil foram, igualmente, pontos importantes nesse trabalho de transmissão de pensamento econômico levado a cabo por Gudin.

Consideramos importante marcar, por fim, que não desejamos defender ou atacar as ideias ou a agenda econômica de Gudin ou dos autores com os quais manteve contato. Com esta pesquisa esperamos puramente contribuir para a literatura sobre o pensamento econômico brasileiro demonstrando que Eugênio Gudin, de modo pioneiro, empreendeu um esforço genuíno de constante atualização, absorção e transmissão das ideias da academia internacional para um país periférico, onde a academia em economia ainda era bastante incipiente.

\section{Fontes Primárias}

Arquivos Pessoais de Eugênio Gudin. Centro de Pesquisa e Documentação de História Contemporânea do Brasil. Fundação Getúlio Vargas, Rio de Janeiro, RJ.

Jacob Viner Papers. Seeley G. Mudd Manuscript Library. Princeton University, Princeton, NJ. Raúl Prebisch Papers. Besa Garcia, José F. (Ed). Archivo de Trabajo. CEPAL, Santiago, Chile.

\section{Referências}

ANDRADA, A. F. S.; BOIANOVSKY, M.; CABELLO, A. F. O clube dos economistas e a revista econômica brasileira (1955-1964): um episódio na história do desenvolvimentismo nacionalista no Brasil. Estudos Econômicos, v. 48, n. 4, p. 721-756, 2018.

BIELSCHOWSKY, R. Pensamento econômico brasileiro: o ciclo ideológico do desenvolvimentismo. 3 ed. Rio de Janeiro: Contraponto, 1996.

BIELSCHOWSKY, R. Pensamento econômico brasileiro: o ciclo ideológico do desenvolvimentismo. Rio de Janeiro: Contraponto, 2000.

BIELSCHOWSKY, R. Eugênio Gudin. Estudos Avançados, v. 15, n. 41, p. 91-110, 2001.

BIELSCHOWSKY, R. O desenvolvimentismo: do pós-guerra até meados dos anos 1960. In: BIELSCHOWSKY, R. et al. O desenvolvimento econômico brasileiro e a Caixa: palestras. Rio de Janeiro: Centro Internacional Celso Furtado: Caixa Econômica Federal, 2011.

BOBULESCU, R. Protectionism in retrospect: Mihail Manoilescu (1891-1950?). Revista Brasileira de Economia Política, v. 23, n. 4, p. 114-123, 2003. 
BOIANOVSKY, M. Celso Furtado and the structuralist monetarist debate on economic stabilization in Latin America. History of Political Economy, v. 44, n. 2, p. 277-330, 2012.

BOIANOVSKY, M. The Brazilian connection in Milton Friedman's 1967 Presidential Address and 1976 Nobel Lecture. In: XLVI ENCONTRO NACIONAL DE ECONOMIA DA ANPEC, 2018. Anais eletrônicos [...]. Rio de Janeiro: ANPEC, 2018.

CAMPOS, R. Roberto de Oliveira Campos. In: BIDERMAN, C.; COZAC, L. F. L.; REGO, J. M. Conversas com economistas brasileiros. São Paulo: Editora 34, 1996. Entrevista.

CAVALIERI, M. A. R.; CURADO, M. L. As influências norte-americanas de Roberto Simonsen: controle social, institucionalismo e planejamento. Estudos Econômicos, v. 46, n. 2, p. 409-438, 2016.

CRUZ E SILVA, V. Economia keynesiana ou a economia de Keynes? Notas sobre a transmissão do ideário de Keynes no Brasil através do livro "Princípios de Economia Monetária” de Eugênio Gudin. 78f. Dissertação (Mestrado) - Universidade Federal do Paraná, Curitiba, 2016.

CRUZ E SILVA, V.; CAVALIERI, M. A. R.; CURADO, M. L. On the transmission of Keynes' and Keynesian ideas in Brazil through Eugênio Gudin's Principles of Monetary Economics. The European Journal of the History of Economic Thought, p. 1-20, 2020. DOI 10.1080/09672567.2020.1776357, 2020.

CURI, L. F. B. Entre a história e a economia: o pensamento econômico de Roberto Simonsen. 1 ed. São Paulo: Alameda: FAPESP, 2015.

CURI, L. F. B.; CUNHA, A. M. Redimensionando a contribuição de Roberto Simonsen à controvérsia do planejamento (1944-1945). América Latina en la Historia Económica, v. 22, n. 3, p. 76-107, 2015.

DOSMAN, E. J. The life and times of Raúl Prebisch, 1901-1986. Canadá: McGill-Queen’s University Press, 2008.

FURTADO, C. A fantasia organizada. Rio de Janeiro: paz e terra, 1985.

GUDIN, E. Princípios de economia monetária. 1 ed. Rio de Janeiro: Editora Civilização Brasileira S/A, 1943a.

GUDIN, E. Produtividade e preços. In: I CONGRESSO BRASILEIRO DE ECONOMIA, 1943. Anais eletrônicos [...]. Rio de Janeiro: Associação Comercial do Rio de Janeiro, 1943b.

GUDIN, E. Princípios de economia monetária. 2 ed. Rio de Janeiro: Agir, 1947.

GUDIN, E. Princípios de economia monetária. 3 ed. Rio de Janeiro: Agir, 1952a, v. 2.

GUDIN, E. O caso das nações subdesenvolvidas. Revista Brasileira de Economia, v. 6, n. 3, p. 47-77, 1952b.

GUDIN, E. Princípios de economia monetária. 3 ed. Rio de Janeiro: Agir, 1954a, v. 1.

GUDIN, E. Produtividade. Revista Brasileira de Economia, v. 8, n. 3, p. 9-70, $1954 \mathrm{~b}$. 
GUDIN, E. Análise dos problemas brasileiros. Rio de Janeiro: Agir, 1965.

GUDIN, E. Rumos de política econômica. In: GUDIN, E.; SIMONSEN, R. A controvérsia do planejamento na economia brasileira. 3 ed. Rio de Janeiro: IPEA, 2010.

HABERLER, G. Problemas de conjuntura e de política econômica. Rio de Janeiro: Editora da Fundação Getúlio Vargas, 1948.

HAGEN, E. An economic justification of protectionism. The Quarterly Journal of Economics, v. 72, n. 4, p. 496-514, 1958.

INSTITUTO BRASILEIRO DE GEOGRAFIA E ESTATÍSTICA. Estatísticas do século XX. Brasília: IBGE, 2003. Disponível em: https://ww2.ibge.gov.br/home/presidencia/noticias/290920 03estatisticasecxxhtml.shtm?fbclid =IwAR21 cglowV51udzGCYB6pxpgeA05VyNzdv2x36EMb WSjBg09QFyF3qFT_Ys. Acesso em: 09 abr. 2019.

LOUREIRO, M. R. The professional and political impacts of the internationalization of economics in Brazil. History of Political Economy, v. 28, p. 184-207, 1996. Suplemento.

LOVE, J. L. Crafting the third world: theorizing underdevelopment in Rumania and Brazil. Stanford: Stanford University Press, 1996.

LOVE, J. L. The roots of unequal exchange: Mihail Manoilescu and the debate of the 1930s. In: KATTEL, R.; REINERT, E. (Eds.). Ragnar Nurkse (1907-2007): classical development economics and its relevance for today. Londres: Anthem Press, 2009.

MACHLUP, F. The theory of foreign exchanges. Economica, v. 7, n. 25, p. 23-49, 1940.

MANESCHI, A. Mihail Manoilescu: an appreciation and a critique. Journal of Forecasting Economics, v. 5, n. 1, p. 130-133, 2008.

MANOILESCU, M. Teoria do protecionismo e da permuta internacional. São Paulo: Escola Profissionaes do Lyceu Coração de Jesus, 1931.

MIROWSKI, P.; PLEHWE, D. The road from Mont Pèlerin: the making of the neoliberal thought collective. Cambridge: Harvard University Press, 2009.

OLIVEIRA, I. R. Missão Cooke: estado novo e a implantação da CSN. Rio de Janeiro: E-papers, 2003.

OMAN, C. P.; WIGNARAJA, G. The postwar evolution of development thinking. Basingstoke: Palgrave Macmillan, 1991.

PERROTA, C. The brilliant fifties. In: SUNNA, C.; GUALERZI, D. Development economics in the twenty-first century. Nova York: Routledge, 2016.

PIGOU, A.; ROBERTSON, D. Economic essays and addresses. Londres: P.S. King, 1931.

PREBISCH, R. O desenvolvimento da América Latina e seus principais problemas. Revista Brasileira de Economia, v. 3, n. 3, p. 47-111, 1949. 
PRIMI, A. Nurkse and the early Latin American structuralists: a reflection on development theory, industrialization and their relevance today. In: KATTEL, R.; REINERT, E. (Eds.). Ragnar Nurkse (1907-2007): classical development economics and its relevance for today. Londres: Anthem Press, 2009.

REVISTA BRASILEIRA DE ECONOMIA. Rio de Janeiro: FGV, 2019. Disponível em: http:// bibliotecadigital.fgv.br/ojs/index.php/rbe/index. Acesso em: 09 abr. 2019.

RUTHERFORD, M. The institutionalist movement in american economics, 1918-1947: science and social control. Cambridge: Cambridge University Press, 2011.

SCALERCIO, M.; ALMEIDA, R. Eugênio Gudin: inventário de flores e espinhos - um liberal em estado puro. Rio de Janeiro: Insight, 2012, p. 24-208.

SCHUMPETER, J.; COLE, A. H.; MASON, E. S. Franklin William Taussig. The Quarterly Journal of Economics, v. 55, n. 3, p. 337-363, 1941.

SILVA, H. S. A elasticidade da procura norte-americana de café. Revista Brasileira de Economia, v. 3, n. 4, p. 83-100, 1949.

SIMONSEN, M. H. Eugênio Gudin e a teoria da inflação. In: KAFKA, A. Eugênio Gudin visto por seus contemporâneos. Rio de Janeiro: Editora da Fundação Getúlio Vargas, 1979.

VINER, J. Mihail Manoilesco on the theory of protection. Journal of Political Economy, v. 40, n. 1, p. 121-125, 1932.

VINER, J. Full employment at whatever cost. The Quarterly Journal of Economics, v. 64, n. 3, p. 385-407, 1950.

VINER, J. Tendências recentes na teoria do mecanismo do comércio internacional. Revista Brasileira de Economia, v. 5, n. 2, p. 37-71, 1951 a.

VINER, J. A economia do desenvolvimento. Revista Brasileira de Economia, v. 5, n. 2, p. 181-225, 1951b.

VON DOELLINGER, C. Introdução. In: GUDIN, E.; SIMONSEN, R. A controvérsia do planejamento na economia brasileira. 3 ed. Rio de Janeiro: IPEA, 2010.

Autor correspondente:

Ivan Gambus Faria

E-mail: gambus.faria@gmail.com
Recebido em: 15/09/2018.

Aceito em: 03/06/2019. 